\title{
TITLE:
}

\section{Credit Market Imperfections and Macroeconomic Instability}

$\operatorname{AUTHOR}(\mathrm{S}):$

Kunieda, Takuma; Shibata, Akihisa

\section{CITATION:}

Kunieda, Takuma ...[et al]. Credit Market Imperfections and

Macroeconomic Instability. Pacific Economic Review 2014, 19(5): 592-

611

\section{ISSUE DATE:}

2014-12

URL:

http://hdl.handle.net/2433/199652

\section{RIGHT:}

This is the peer reviewed version of the following article: Kunieda, T. and Shibata, A. (2014), Credit Market Imperfections and Macroeconomic Instability. Pacific Economic Review, 19: 592-611, which has been published in final form at

http://dx.doi.org/10.1111/1468-0106.12085. This article may be used for non-commercial purposes in accordance with Wiley Terms and Conditions for Self-Archiving.; 許諾条件により本文ファイルは2015-12-23に公開.; This is not the published version. Please cite only the published version.; この論文は出版社版でありません。引用の際には出版社版 をご確認ご利用ください。 


\title{
CREDIT MARKET IMPERFECTIONS AND MACROECONOMIC INSTABILITY
}

\author{
Takuma Kunieda City University of Hong Kong \\ Akihisa Shibata*Kyoto University
}

Abstract. Credit market imperfections typically characterize a low quality financial market, where the quality of information about borrowers is low and/or enforcement rules or institutions are not well developed. We consider an economy with credit market imperfections and analyze how changes in the degree of credit constraints affect economic fluctuations. The analysis demonstrates that if the degree of credit market imperfection is either severe or too soft, the economy converges to an asymptotically stable steady state, whereas if the degree of imperfection is moderate, the equilibrium involves deterministic cycles or chaos.

*Address for Correspondence: Institute of Economic Research, Kyoto University, Yoshida-Honmachi, Sakyo-ku, Kyoto 606-8501, JAPAN. E-mail: shibata@kier.kyotou.ac.jp. Shibata has received financial support from JSPS Grant-in-Aid for Specially Promoted Research (No.23000001) and JSPS Grant-in-Aid for Scientific Research (No. 23330060), and Kunieda has received financial support from City University of Hong Kong (No. 7200307). The authors would like to express thanks to an anonymous referee, Hiroki Arato, Costas Azariadis, Volker Böhm, Raouf Boucekkine, Oded Galor, Takeo Hori, Peter Howitt, Tomoo Kikuchi, Kazuo Mino, Kazuo Nishimura, Makoto Saito, Masaya Sakuragawa, Etsuro Shioji, Zheng Michael Song, Alain Venditti, David Weil, and seminar participants at the Chinese University of Hong Kong and Hitotsubashi University, and participants of the 2011 APJAE Symposium on Dynamic System and World Trade at City University of Hong Kong and the 4th Workshop on Macroeconomic Dynamics at National University of Singapore for their comments. All remaining errors, if any, are ours. 


\section{INTRODUCTION}

Developing a new economic theory of market quality, Yano (2008, 2009) emphasizes that high market quality is an essential precondition for achieving healthy economic growth and that the lack of high quality markets causes fundamental malfunctions in the market allocation mechanism. According to Yano $(2008,2009)$, the basic determinants of market quality are the quality of competition, quality of information, and product quality. To assure high quality of competition and information, we require the establishment of solid market infrastructure, such as fair laws and rules, healthy institutions and organizations, and good culture and customs.

Thus far, several researchers have addressed these basic determinants of market quality. Focusing on the labor market, Dei (2011) models a developing economy in which the quality of the labor market is endogenously determined through voting, and shows that if the voting takes place at the wrong time, the country suffers from a low quality labor market. Ma and Dei (2009) examine the issue of product quality in a model of Chinese trade. Furukawa (2010) applies the market quality theory to the intellectual property rights market in a dynamic setting. These studies, which belong to the market quality literature, do not deal with the quality of financial markets. In contrast, Savtchenko (2010) investigates the quality of information in the international financial market. Savtchenko states, "markets characterized by currency crises cannot be called high quality markets," and shows that, when economic agents possess only private information, a currency crisis in a country can be triggered by a similar event in another country. Our paper also deals with the quality of financial markets, but unlike Savtchenko (2010), we consider a closed economy that faces credit constraints, and explicitly investigate how the degree of credit constraints affects economic fluctuations. It should be noted here that low quality financial markets are typically characterized by the presence of credit constraints. This may reflect the poor quality of information about borrowers and/or the lack of well-developed enforcement rules or institutions in such markets.

There are two major reasons why we focus on financial markets. First, a large number of economists, in the tradition of Keynes (1936), have viewed the financial sector as the source of business fluctuations. Second, there is much empirical support for this view. For example, several well-known historical episodes, such as the Great Depression before World War II, the lost decade in Japan after the boom of the 1980s, and the sub-prime loan 
problems in the late 2000s, are consistent with this view. More recently, several researchers such as Easterly et al. (2000), Denizer et al. (2002), and Beck et al. (2006) have presented empirical evidence indicating that financial development has a negative effect on the volatility of an economy.

In our model, agents within the same generation are heterogeneous with respect to their productivity in creating capital goods. Each agent has two saving methods. The first involves depositing a part of one's wage income in a financial intermediary, and the second is to start an investment project. In equilibrium, less talented agents deposit part of their wage income in the financial intermediary, and do not start investment projects. They are analogous to the agents in Samuelson's consumption loan model. On the other hand, agents that are more talented start investment projects. These parallel the agents in Diamond's production economy. Our main result is as follows. If credit constraints are either severe or too soft, an economy converges to an asymptotically stable steady state, but if credit constraints are moderate, deterministic cycles or chaos can arise.

We use the degree of credit constraints to denote the degree of financial development: as the financial sector develops, credit constraints are relaxed. Moreover we employ Cobb-Douglas utility and production functions. With Cobb-Douglas utility and production functions, a perfect financial market does not generate endogenous business cycles; however, an imperfect financial market might do so. This fact indicates that the chaotic dynamics in our model arise due to the moderate degree of financial development.

The rest of the paper is organized as follows. In the next section, we discuss the literature related to our study. The model is presented in section 3. In section 4 , we derive a competitive equilibrium, and in section 5 , we investigate the dynamic properties of the economy. In section 6 , we provide a discussion about the degree of credit constraints under which endogenous business cycles are most likely to occur. In section 7 , we execute a numerical analysis, and we provide concluding remarks in section 8 .

\section{RELATED LITERATURE}

Bernanke and Gertler (1989) and Kiyotaki and Moore (1997) develop dynamic general equilibrium models with credit constraints, and show that a negative productivity shock can have a prolonged negative effect on the 
macroeconomy; ${ }^{1}$ however, they do not clarify what degree of credit constraints is most likely to give rise to high volatility. Furthermore, their models do not derive endogenous business cycles. In contrast, the business cycles in our model are endogenous, and we investigate under what degree of credit constraints these endogenous cycles are more likely to occur. In a small open economy under the intermediate degree of credit constraints, Aghion et al. (2004) and Caballé et al. (2006) derive deterministic endogenous cycles and Pintus (2011) obtains endogenous cycles caused by self-fulfilling expectations. Aghion et al. (1999) derive endogenous cycles in a closed economy under the intermediate degree of credit constraints. As in Aghion et al. (1999), we obtain endogenous business cycles for a closed economy under an intermediate degree of credit constraints. Unlike Aghion et al. (1999), however, the current study develops an overlapping generations model with hybrid aspects of Samuelson (1958) and Diamond (1965). Because of the hybrid aspects, we can construct a tractable model into which credit market imperfections are easily incorporated.

This paper contributes to an extensive literature on endogenous business fluctuations in overlapping generations economies. ${ }^{2}$ Benhabib and Day (1982) and Grandmont (1985) gave rise to a literature investigating the dynamic properties of exchange economies. This literature examines deterministic cycles and chaotic behavior in equilibrium. ${ }^{3}$ On the other hand, another strand of the literature studies the dynamic properties of overlapping generations economies with production in the tradition of Diamond (1965). For instance, Farmer (1986), Reichlin (1986), Benhabib and Laroque (1988), and Rochon and Polemarchakis (2006) derive competitive equilibrium cycles in a production economy. Galor (1992) demonstrates the dynamic properties of an overlapping generations economy with two produc-

\footnotetext{
${ }^{1}$ Kiyotaki (1998) explains the basic mechanism of this result in a clear way. Many researchers have extended these models in several directions. For example Aoki et al. (2009), Kunieda and Shibata (2005), and Paashce (2001) have extended the Kiyotaki and Moore type model to open economies. See Gertler and Kiyotaki (2010) and Kiyotaki (2011) for surveys on recent developments.

${ }^{2}$ Another influential approach to endogenous business cycles was pioneered by Benhabib and Nishimura (1985). Studies in this line employ infinitely lived representative agent models to show the possibility of endogenous business cycles. For example, Nishimura and Yano (1995) develop a simple two-sector model with Leontief-type technologies, and show that endogenous business cycles and chaotic dynamics can be generated in the model.

${ }^{3}$ Azariadis and Guesnerie (1986) and Guesnerie (1986) study sunspot equilibria of exchange economies by using overlapping generations models.
} 
tion sectors. None of these articles explicitly considers credit constraints. In contrast, Gokan (2011), Kikuchi (2008), Kikuchi and Stachurski (2009), Kikuchi and Vachadze (2013), and Matsuyama (2007, 2013) study creditconstrained economies. ${ }^{4}$ These studies do not investigate how changes in the degree of credit constraints affect economic fluctuations. In particular, Gokan (2011) develops an overlapping generations model with money and shows that a monetary equilibrium path can exhibit cyclical movements. However, the analysis of the relationship between the degree of credit constraints and macroeconomic instability is absent in his paper, unlike in ours.

\section{MODEL}

\subsection{Individuals}

The economy consists of overlapping generations: young and old. Time is discrete and expands from 0 to $\infty$. Each individual lives for two periods and the population of young agents at time $t$ is given by $L_{t}$, which grows at rate $n>-1: L_{t+1}=(1+n) L_{t}$. Following Bernanke and Gertler (1989), we may think of a "period" as the length of a typical financial contract. ${ }^{5}$

\footnotetext{
${ }^{4}$ Early influential studies on economic fluctuations, such as Azariadis and Smith (1998) and Suarez and Sussman (1997), carefully consider the microfoundations of credit market imperfections, explicitly taking asymmetric information into account. Many subsequent studies cited here focus more on the effects of credit constraints, taking the microfoundations of credit market imperfections as given. Most recently, Favara (2012) explicitly considers an agency problem between financiers and entrepreneurs, and relates the agency problem with investment instability.

${ }^{5}$ In this setting, each agent makes only one-time investment decision. Although this may seem to be restrictive, it is not difficult to incorporate multiple-time investment opportunities for each agent into our model. For example, we can extend the current model to a Ramsey type growth model of infinitely lived agents with idiosyncratic shocks to agents' productivity in a similar way to Angeletos (2007). Even in this setting, we can derive essentially the same dynamic properties as those of the current model. This extension, however, complicates aggregation of individually specific variables, and thus we must impose an additional assumption about the distribution of productivity shocks, that is, we must assume that the idiosyncratic productivity shocks are independently and identically distributed across both time and agents (the i.i.d. assumption). The virtue of employing the two-period overlapping generations model is that we do not have to impose the i.i.d. assumption because only one generation makes investment decisions in each period.
} 
Each individual maximizes his lifetime utility:

$$
u_{t}\left(c_{1 t}(\phi), c_{2 t+1}(\phi)\right):=c_{1 t}(\phi)^{\gamma} c_{2 t+1}(\phi)^{1-\gamma}, \quad 0<\gamma<1
$$

which is a Cobb-Douglas function of consumption $\left(c_{1 t}(\phi), c_{2 t+1}(\phi)\right)$ in youth and old age. The index $\phi$ expresses the heterogeneity of individuals. As will be explained later, $\phi$ also represents productivity of an individual.

Each individual is endowed with one unit of labor at his birth. When an individual is young, he supplies one unit of labor to a production sector in order to earn wage income $w_{t}$, which is spent for consumption, investments and/or deposits. Since the quality of young labor is even, $w_{t}$ does not vary between agents. The budget constraint in the first period is as follows:

$$
c_{1 t}(\phi)+k_{t}(\phi)+b_{t}(\phi) \leq w_{t},
$$

where $k_{t}(\phi)$ is investment in a project and $b_{t}(\phi)$ is deposits when positive or debts when negative. He has two kinds of transfer methods regarding his wealth from the first to the second period. One is to make a deposit in the financial intermediary. The other is to start an investment project.

An individual can borrow against future income by selling bonds to the financial intermediary. However, he faces a credit constraint characterized by the following inequality:

$$
b_{t}(\phi) \geq-\mu k_{t}(\phi), \quad 0 \leq \mu<1 .
$$

The source of the credit constraints is the possibility that borrowers may not repay the financial intermediary (see Aghion and Banerjee, 2005, Chapter $0)$. Parameter $\mu$ is the measure of financial development. If $\mu$ is close to one, the credit market is perfect, whereas if $\mu$ is equal to zero, there is no credit market in this economy. ${ }^{6}$ by:

The budget constraint the individual faces in the second period is given

$$
c_{2 t+1}(\phi) \leq q_{t+1} z_{t+1}(\phi)+r_{t+1} b_{t}(\phi),
$$

where $z_{t+1}(\phi)$ is the capital goods. Producing the capital goods $z_{t+1}(\phi)$ takes one gestation period and they are created from the investments $k_{t}(\phi)$

\footnotetext{
${ }^{6}$ Eq. (3) is equivalent to $b_{t}(\phi) \geq-a_{t}(\phi) \mu /(1-\mu)$ where $a_{t}(\phi):=k_{t}(\phi)+b_{t}(\phi)$. This type of credit constraint is often employed in the literature. See Aghion et al. (1999), Aghion and Banerjee (2005), Aghion et al. (2005), or Antrás and Caballero (2009). In a similar way to Aghion, et al. (1999), we can give a microfoundation for Eq.(3). A note on the derivation of Eq.(3) is available upon request.
} 
in the first period. $q_{t+1}$ is the (real) price of the capital goods in terms of consumption goods at time $t+1$ and $r_{t+1}$ is the gross interest rate. Income in the second period is spent only for consumption. The production function of $z_{t+1}(\phi)$ is given by:

$$
z_{t+1}(\phi)=\phi k_{t}(\phi),
$$

where $\phi$ is the productivity parameter of an individual. $\phi$ varies between individuals and has a distribution, $G(\phi)$, whose support is $[0, a]$ where $a>0$. We assume $\int_{0}^{a} \phi d G(\phi)<\infty .^{7}$

Each individual maximizes his lifetime utility function subject to Eqs.(2)(5) and

$$
k_{t}(\phi) \geq 0 .
$$

Eq.(6) is a non-negativity constraint for the investments.

From the utility maximization problem, we obtain a lemma as follows:

\section{Lemma 1}

- If $r_{t+1}>\phi q_{t+1}$, then $k_{t}(\phi)=0$ and $b_{t}(\phi)=(1-\gamma) w_{t}$.

- If $r_{t+1}<\phi q_{t+1}$, then $k_{t}(\phi)=\frac{(1-\gamma) w_{t}}{1-\mu}$ and $b_{t}(\phi)=-\frac{\mu(1-\gamma)}{1-\mu} w_{t}$.

Proof: Let $a_{t}(\phi):=k_{t}(\phi)+b_{t}(\phi)$. From the utility maximization problem, we have $a_{t}(\phi)=(1-\gamma) w_{t}$ for any agent. To maximize an income in old age, an agent with $r_{t+1}>\phi q_{t+1}$ chooses $k_{t}(\phi)=0$ and $b_{t}(\phi)=(1-\gamma) w_{t}$ and an agent with $r_{t+1}<\phi q_{t+1}$ chooses $b_{t}(\phi)=-\mu k_{t}(\phi)$, that is, $k_{t}(\phi)=(1-\gamma) w_{t} /(1-\mu)$ and $b_{t}(\phi)=-\mu(1-\gamma) w_{t} /(1-\mu)$.

Let us define $\phi_{t}:=r_{t+1} / q_{t+1}$. Then, $\phi_{t}$ is a cutoff that divides agents into savers and borrowers (investors). From lemma 1 we note that if the productivity of an agent $\phi$ is greater than $\phi_{t}$, he invests a proportion of his income in a project. If the productivity is less than $\phi_{t}$, he does not invest in any project but make a deposit in the financial intermediary.

\subsection{Production Sector}

In a production sector, a representative firm produces consumption goods from capital goods and labor. A Cobb-Douglas production function is as-

\footnotetext{
${ }^{7}$ The productivity of each agent is private information. Each agent learns his productivity at his birth; however, other people do not know his productivity. Accordingly, no one can directly ask another individual whose productivity is greater than his to make capital goods for him.
} 
sumed as follows:

$$
Y_{t}=Z_{t}^{\alpha} L_{t}^{1-\alpha}
$$

where $Y_{t}$ is the total output and $L_{t}$ is the aggregate young labor. $Z_{t}$ is the aggregate capital goods, which is given by $\int_{0}^{a} z_{t}(\phi) L_{t} d G(\phi)$. The capital goods depreciate entirely in one period. The production sector is perfectly competitive so that the production factors, capital goods and labor, are paid their marginal products as follows:

$$
\begin{aligned}
& q_{t}=\alpha z_{t}^{\alpha-1} \\
& w_{t}=(1-\alpha) z_{t}^{\alpha},
\end{aligned}
$$

where $z_{t}:=Z_{t} / L_{t}=\int_{0}^{a} z_{t}(\phi) d G(\phi)$.

\subsection{Financial Intermediary}

There is an intergenerational banking system and agents make financial trades with each other through the financial intermediary. This kind of assumption is made by many researchers. ${ }^{8}$ Since the banking sector is competitive, no profits are obtained by the financial intermediary. The financial intermediary accommodates its supply of real liabilities to young agents so that the financial market always clears. Let $B_{t}$ be net total assets held by young agents in a generation $t$, i.e., $B_{t}=\int_{0}^{a} b_{t}(\phi) L_{t} d G(\phi)$. Or equivalently $B_{t}$ is regarded as the debt of the financial intermediary. The budget constraint of the financial intermediary is given by

$$
B_{t+1}=r_{t+1} B_{t} .
$$

The financial intermediary limits its credit provision or liabilities to the private sector following Eq.(10). If (10) holds, the goods market clears as well. Note that $B_{t}$ can be negative or positive. When $B_{t}<0$ in a period, the financial intermediary has the ownership of the economy's net assets; however, these assets will become financial resources lent to young agents in the next period. When $B_{t}>0$, the financial intermediary is indebted to the private agents. The financial intermediary redeems this indebtedness by using a net deposit in the next period. $B_{0}$ is a predetermined variable since we do not assume the existence of nominal money in this economy. At time zero, the financial intermediary can be a net creditor or a net debtor to the private sector.

\footnotetext{
${ }^{8}$ See for example Grandmont (1983), Farmer (1986), Benhabib and Laroque (1988), and Rochon and Polemarchakis (2006).
} 


\section{EQUILIBRIUM}

\subsection{Competitive Equilibrium}

In competitive equilibrium, we obtain the aggregate supply of capital goods and the total net assets held by young agents. From lemma 1 and Eq.(9), the aggregate supply of capital goods is given by:

$$
Z_{t+1}=\int_{\phi_{t}}^{a} \frac{(1-\gamma)(1-\alpha) z_{t}^{\alpha}}{1-\mu} \phi L_{t} d G(\phi) \Longleftrightarrow z_{t+1}=\frac{(1-\gamma)(1-\alpha) F\left(\phi_{t}\right)}{(1+n)(1-\mu)} z_{t}^{\alpha},
$$

where $F\left(\phi_{t}\right):=\int_{\phi_{t}}^{a} \phi d G(\phi)$. From lemma 1 and Eq.(9), we obtain:

$$
\begin{aligned}
B_{t} & =\int_{0}^{\phi_{t}}(1-\gamma)(1-\alpha) z_{t}^{\alpha} L_{t} d G(\phi)+\int_{\phi_{t}}^{a} \frac{-\mu(1-\gamma)(1-\alpha) z_{t}^{\alpha}}{1-\mu} L_{t} d G(\phi) \\
& =\frac{(1-\gamma)(1-\alpha) z_{t}^{\alpha} L_{t}}{1-\mu}\left[G\left(\phi_{t}\right)-\mu\right]
\end{aligned}
$$

From lemma 1, $r_{t+1}=q_{t+1} \phi_{t}=\alpha z_{t+1}^{\alpha-1} \phi_{t}$ and Eqs.(9)-(12), we obtain:

$$
G\left(\phi_{t+1}\right)=\frac{\alpha(1-\mu)}{(1-\alpha)(1-\gamma)} \frac{\phi_{t}\left(G\left(\phi_{t}\right)-\mu\right)}{F\left(\phi_{t}\right)}+\mu
$$

The dynamical system in competitive equilibrium consists of Eqs.(11) and (13). Fortunately, Eq.(13) is a one-dimensional difference equation with respect to $\phi_{t}$. We focus our study on this equation for awhile. Let us define a function as follows:

$$
\Psi(\phi):=\frac{\alpha(1-\mu)}{(1-\alpha)(1-\gamma)} \frac{\phi(G(\phi)-\mu)}{F(\phi)}+\mu,
$$

which is the right-hand side of Eq.(13). Note that the difference equation Eq.(13) is independent of population growth.

\subsection{Steady States}

There exist two steady-state equilibria $\phi^{*}$ and $\phi^{* *}$ in Eq. (13) such that:

$$
G\left(\phi^{*}\right)=\mu
$$


and

$$
\frac{\phi^{* *}}{F\left(\phi^{* *}\right)}=\frac{(1-\alpha)(1-\gamma)}{\alpha(1-\mu)}
$$

respectively.

The net total assets held by young agents is always zero in the steadystate equilibrium with $\phi^{*}$. We call this steady state a non-trade steady state. Meanwhile, in the steady-state equilibrium with $\phi^{* *}$, the net total assets in a generation is positive or negative, i.e., the steady-state equilibrium is supported by credit or debt of the financial intermediary. We call this steady state a trade steady sate. In the non-trade steady state, the borrowing and the lending within a generation are canceled out, whereas in the trade steady state, the credit market clears over two generations. Either in the trade steady state or in the non-trade steady state, there are both borrowers and lenders within a generation generically. ${ }^{9}$

Gale (1973) and Grandmont (1983) categorized an economy into two classes. An economy in which the trade steady state is supported by debt of the financial intermediary is called the Samuelsonian case, whereas an economy in which the trade steady state is supported by credit is called the classical case. From Eq.(12), it follows that the economy is Samuelsonian (classical) if and only if $\phi^{*}<(>) \phi^{* *}$. If $\mu=0$, then we obtain $\phi^{*}=0$ and $\phi^{* *}>0$. Then, by continuity, there exist $\mu_{s} \in \Re_{++}$such that for $\mu \in\left[0, \mu_{s}\right)$, the economy is Samuelsonian. If the credit constraints are severe or if each individual puts the weight of his utility on the second-period consumption, it is likely that the economy is the Samuelsonian case. This is consistent with our intuition, because every individual does not borrow so much in the Samuelsonian case.

As we said, a trade steady state is supported by credit or debt of the financial intermediary. In usual overlapping generations models, such a steady state coincides with the golden rule. However, our trade steady state never coincides with the golden rule. This is due to credit constraints. Since the investors face credit constraints, economic resources cannot be used in an efficient way. It is a necessary condition for the economy to attain the golden rule that all resources are used by the most talented agents. Although a trade steady state never becomes the golden rule, we can easily verify that

\footnotetext{
${ }^{9}$ One might argue that we should call the steady state with $\phi^{* *}$ the golden rule steady state; however, this argument is misleading because, as discussed in what follows, the steady state with $\phi^{* *}$ never maximizes per capita consumption in the economy due to credit constraints.
} 
less talented agents obtain the biological interest rate $\bar{r}=1+n$ in the steady state. This means that all agents obtain at minimum the biological interest rate in their second period while the economy cannot attain the golden rule.

In the Diamond-type overlapping generations models without the heterogeneity of agents within a generation, if the golden rule is supported by national debt, then the golden-rule steady state and the Diamond steady state (which correspond to our trade and non-trade steady states, respectively) are Parato-ranked. However, our trade and non-trade steady states can never be Parato-ranked. This is because of the heterogeneity of agents and because of credit constraints.

\section{DYNAMIC PROPERTIES}

We define a compact interval in $\Re$ as $X=\left[0, \max \left\{\phi^{*}, \phi^{* *}\right\}\right]$. If $\left\{\phi_{t}\right\}_{t=0}^{\infty}$ starts with $\phi_{0} \in\left(\max \left\{\phi^{*}, \phi^{* *}\right\}, a\right]$, then $G\left(\phi_{t}\right)$ becomes greater than one in finite time. Therefore, such a sequence does not become equilibrium. We restrict the domain of the dynamical system of Eq.(13) to $X$.

We assume that the minimum of $\Psi(\phi)$ is no less than zero unless we explicitly state otherwise. As will be discussed in section 6 , if the minimum of $\Psi(\phi)$ is less than zero, for almost all the initial value of $\phi_{0}$ no equilibrium exists since for almost all the initial value of $\phi_{0}$, the sequence $\left\{\phi_{t}\right\}_{t=0}^{\infty}$ exits from the domain of the dynamical system in finite time. Only when $\phi_{0}$ is consistent with the existence of equilibrium by accident, the sequence $\left\{\phi_{t}\right\}_{t=0}^{\infty}$ could be equilibrium (see section 6 ).

If the domain of the dynamical system is restricted to $X$, then the map, $\Psi: X \rightarrow X$, is continuous, mapping $X$ into itself. Henceforth, we use the pair $(X, \Psi)$ to denote our dynamical system. In what follows, we investigate the local and global dynamic properties of the economy. We linearize the difference equation Eq.(13) around a steady state as follows:

$$
\phi_{t+1}-\bar{\phi}=\Phi(\bar{\phi})\left(\phi_{t}-\bar{\phi}\right),
$$

where $\bar{\phi}=\phi^{*}$ or $\phi^{* *}$ and $\Phi(\phi)=\frac{\alpha(1-\mu) \phi}{(1-\alpha)(1-\gamma) F(\phi)}\left[\left(\frac{1}{\phi g(\phi)}+\frac{\phi}{F(\phi)}\right)(G(\phi)-\mu)+1\right]$.

While the initial value $\phi_{0}$ reflects the individuals' expectations for the price of capital goods $\left(q_{1}\right)$ and the interest rate $\left(r_{1}\right)$, it is predetermined since $B_{0}$ is historically given (see Eq.(12)). This implies that the individuals cannot have anticipations for $q_{1}$ and $r_{1}$ independently at time zero: the 
anticipations for $q_{1}$ and $r_{1}$ are restricted by the amount of $B_{0}$. Henceforth, we assume that $B_{0}$ is small so that an equilibrium can exist.

\section{Proposition 1}

- If the economy is Samuelsonian, then the non-trade steady state is locally stable, whereas the trade steady state is locally unstable.

- If the economy is classical, then the non-trade steady state is locally unstable, whereas the stability of the trade steady state is ambiguous.

Proof: If the economy is Samuelson, then $\phi^{*}<\phi^{* *}$. Therefore, $\left|\Phi\left(\phi^{*}\right)\right|=$ $\left|\frac{\alpha(1-\mu) \phi^{*}}{(1-\alpha)(1-\gamma) F\left(\phi^{*}\right)}\right|<\left|\frac{\alpha(1-\mu) \phi^{* *}}{(1-\alpha)(1-\gamma) F\left(\phi^{* *}\right)}\right|=1$ and $\left|\Phi\left(\phi^{* *}\right)\right|=\mid\left(\frac{1}{\phi^{* *} g\left(\phi^{* *}\right)}+\frac{\phi^{* *}}{F\left(\phi^{* *}\right)}\right) \times$ $\left(G\left(\phi^{* *}\right)-\mu\right)+1 \mid>1$. If the economy is classical, then $\phi^{*}>\phi^{* *}$. Therefore, $\left|\Phi\left(\phi^{*}\right)\right|=\left|\frac{\alpha(1-\mu) \phi^{*}}{(1-\alpha)(1-\gamma) F\left(\phi^{*}\right)}\right|>\left|\frac{\alpha(1-\mu) \phi^{* *}}{(1-\alpha)(1-\gamma) F\left(\phi^{* *}\right)}\right|=1$. However, we cannot know about whether $\left|\Phi\left(\phi^{* *}\right)\right|=\left|\left(\frac{1}{\phi^{* *} g\left(\phi^{* *}\right)}+\frac{\phi^{* *}}{F\left(\phi^{* *}\right)}\right)\left(G\left(\phi^{* *}\right)-\mu\right)+1\right|$ is greater than one or not.

The phase diagrams of each case are given by figure 1. As seen in panel III, if the trade steady state is locally unstable, it is possible that the dynamical system will exhibit either cycles or chaos. At minimum, when the trade steady state is locally unstable, there exists a period-two cycle.

[Figure 1 around here]

\section{Proposition 2}

Suppose that $\phi^{* *}<\phi^{*}$. If the trade steady state is locally unstable, there exists a period-two cycle of $\left\{\phi_{t}\right\}_{t=0}^{\infty}$ in equilibrium.

Proof: Let $\tilde{\Psi}(\phi)=G^{-1}(\Psi(\phi))$. Then Eq.(13) is written as $\phi_{t+1}=\tilde{\Psi}\left(\phi_{t}\right)$. Since $\Phi\left(\phi^{*}\right)>1$, We can take $\phi_{0}$ close to $\phi^{*}$ so that $\tilde{\Psi}^{2}\left(\phi_{0}\right)<\phi_{0}<\phi^{*}$. If the steady-state equilibrium with $\bar{\phi}=\phi^{* *}$ is locally unstable, then $\Phi\left(\phi^{* *}\right)<$ -1 . So we can take $\phi_{0}^{\prime}$ close to $\phi^{* *}$ so that $\phi^{* *}<\phi_{0}^{\prime}<\tilde{\Psi}^{2}\left(\phi_{0}^{\prime}\right)<\tilde{\Psi}^{2}\left(\phi_{0}\right)$. Therefore, by continuity, there exists $\bar{\phi}_{0}$ such that $\phi^{* *}<\bar{\phi}_{0}=\widetilde{\Psi}^{2}\left(\bar{\phi}_{0}\right)<\phi^{*}$, which means that there exists a period-two cycle.

When $\left\{\phi_{t}\right\}_{t=0}^{\infty}$ exhibits a period-two cycle, the sequence of capital stock $\left\{z_{t}\right\}_{t=0}^{\infty}$ converges to a period-two cycles as well. ${ }^{10}$ This claim is proven as

\footnotetext{
${ }^{10}$ Even though a period-two cycle of $\left\{\phi_{t}\right\}_{t=0}^{\infty}$ exists, it might or might not be globally stable. If the period-two cycle is globally stable, then for any initial value of $\phi_{0}$, the
} 
follows. Without loss of generality, we can suppose that $\left\{\phi_{t}\right\}_{t=0}^{\infty}$ takes the values as $\phi_{2 t}=\phi_{L}$ and $\phi_{2 t+1}=\phi_{H}$ for $t \geq 0$, where $\phi_{L}<\phi_{H}$. From Eq.(11), we obtain the law of motion of capital stock for odd periods and for even periods respectively as follows:

$$
z_{2 t+1}=F\left(\phi_{L}\right) F\left(\phi_{H}\right)^{\alpha}\left[\frac{(1-\gamma)(1-\alpha)}{(1+n)(1-\mu)}\right]^{1+\alpha} z_{2 t-1}^{\alpha^{2}}
$$

and

$$
z_{2(t+1)}=F\left(\phi_{H}\right) F\left(\phi_{L}\right)^{\alpha}\left[\frac{(1-\gamma)(1-\alpha)}{(1+n)(1-\mu)}\right]^{1+\alpha} z_{2 t}^{\alpha^{2}} .
$$

From Eq.(16), since $0<\alpha^{2}<1$, the capital stock in odd periods converges to $\bar{z}^{o}:=\left[F\left(\phi_{L}\right) F\left(\phi_{H}\right)^{\alpha}\right]^{\frac{1}{1-\alpha^{2}}}\left[\frac{(1-\gamma)(1-\alpha)}{(1+n)(1-\mu)}\right]^{\frac{1}{1-\alpha}}$. Likewise, the capital stock in even periods converges to $\bar{z}^{e}:=\left[F\left(\phi_{H}\right) F\left(\phi_{L}\right)^{\alpha}\right]^{\frac{1}{1-\alpha^{2}}}\left[\frac{(1-\gamma)(1-\alpha)}{(1+n)(1-\mu)}\right]^{\frac{1}{1-\alpha}}$. Obviously, $\bar{z}^{o} \neq \bar{z}^{e}$ and thus $\left\{z_{t}\right\}_{t=0}^{\infty}$ converges to a period-two cycle. Figure 2 demonstrates the dynamic behavior of the sequence $\left\{z_{t}\right\}_{t=0}^{\infty}$. Since $F\left(\phi_{L}\right)>F\left(\phi_{H}\right)$, it holds that $\bar{z}^{o}>\bar{z}^{e}$. This claim for period-two cycles can be easily applied to period- $n$ cycles, although we omit the formal proof for this. That is to say, if we suppose that $\{\phi\}_{t=0}^{\infty}$ exhibits a period- $n$ cycle, $\left\{z_{t}\right\}_{t=0}^{\infty}$ converges to a period- $n$ cycle as well.

[Figure 2 around here]

\section{CHAOTIC BUSINESS CYCLES}

To see under what degree of financial development the economy experiences endogenous business fluctuations, we examine two extreme cases in which $\mu=0$ and in which $\mu$ is very close to one. If $\mu=0$, then it follows from Eqs.(14) and (15) that $\phi^{*}=0$ and $\phi^{* *}>0$. In this case, since the economy is Samuelsonian, we note from proposition 1 that no cycles appear in equilibrium. By continuity, there exits $\mu^{L} \in(0,1)$ such that for $\mu \in\left[0, \mu^{L}\right)$, no

sequence $\left\{\phi_{t}\right\}_{t=0}^{\infty}$ converges to it. If the period-two cycle is not globally stable, then the economy exhibits the period-two cycle only when the initial value of $\phi_{0}$ is equal to $\bar{\phi}_{0}$ in the above proof by accident. 
cycles appear in equilibrium. If $\mu$ is very close to one, then the first term of Eq.(13) degenerates. In this case, obviously no cycles appear, either. Again, by continuity, there exists $\mu^{H} \in(0,1)$ such that for $\mu \in\left(\mu^{H}, 1\right)$, no cycles appear. Therefore, it is when financial sector development is at an intermediate level that endogenous business cycles can appear in equilibrium.

From the proof of the second part of proposition 1, we note that if $\left(\frac{1}{\phi^{* *} g\left(\phi^{* *}\right)}+\frac{\phi^{* *}}{F\left(\phi^{* *}\right)}\right)\left(G\left(\phi^{* *}\right)-\mu\right)<-2$, the economy exhibits endogenous cycles because the steady state with $\bar{\phi}=\phi^{* *}$ is locally unstable. ${ }^{11}$ This inequality implies that if an economy is classical (i.e., $G\left(\phi^{* *}\right)<\mu$ ) and if the population density around $\phi=\phi^{* *}$ is very small (that is to say, $g\left(\phi^{* *}\right)$ is very small), then the economy exhibits endogenous business cycles.

Intuitively, the appearance of endogenous business cycles is explained by the demand for and supply of financial resources. Let us suppose that the economy is classical and $\mu$ is an intermediate value. Suppose also that the population density around $\phi=\phi^{* *}$ is so small that the inequality $\left(\frac{1}{\phi^{* *} g\left(\phi^{* *}\right)}+\right.$ $\left.\frac{\phi^{* *}}{F\left(\phi^{* *}\right)}\right)\left(G\left(\phi^{* *}\right)-\mu\right)<-2$ holds. At the beginning, the economy is assumed to be in the trade steady state $\left(\bar{\phi}=\phi^{* *}\right)$. If $B_{t}$ goes up at the beginning of time $t$ for some reason, then $\phi_{t}$ goes up as well. In this case, the financial intermediary can promise savers a higher interest rate than it was for two reasons. The first reason is that if $\phi_{t}$ goes up, then the supply of capital goods becomes small and thus the price of capital goods increases, which is followed by the increase in $r_{t+1}$. The second reason is that since $\phi_{t}$ goes up, the number of less talented agents who are engaged in production becomes smaller than it was. Then, the productivity for creating capital goods increases and thus $r_{t+1}$ rises. If $r_{t+1}$ rises so much, financial resources at time $t+1$ probably increase even though $B_{t}$ goes up (note that $B_{t}$ is negative now.). Therefore, $B_{t+1}$ decreases. If $B_{t+1}$ reduces, then $\phi_{t+1}$ goes down. When the population density around $\phi=\phi^{* *}$ is very small, the reaction of $\phi_{t+1}$ to the slight change of $\phi_{t}$ is very big so as for Eq.(10) to hold. That is why endogenous business cycles appear.

To investigate the dynamic property of the sequence $\left\{\phi_{t}\right\}_{t=0}^{\infty}$ more concretely, we assume that $\phi$ follows a uniform distribution $U(0,1)$ to the end. Accordingly, the difference equation associated with the dynamical system

\footnotetext{
${ }^{11}$ This claim holds even in the case in which the minimum of $\Psi(\phi)$ is less than zero.
} 
$(X, \Psi)$ is given by:

$$
\phi_{t+1}=\Psi\left(\phi_{t}\right)=\frac{2 \alpha(1-\mu)}{(1-\alpha)(1-\gamma)} \frac{\phi_{t}\left(\phi_{t}-\mu\right)}{1-\phi_{t}^{2}}+\mu .
$$

We can verify that $\Psi: X \rightarrow X$ is a (upside-down) unimodal map. Let $m$ be a critical point of this map, i.e., $\Psi^{\prime}(m)=0 . \quad m$ is easily obtained: $m=\frac{\mu}{1+\sqrt{1-\mu^{2}}}$. In order for $\Psi$ to map $X$ into itself, $\Psi(m)$ should be no less than zero. So we continue to assume that the minimum of $\Psi\left(\phi_{t}\right)$ is no less than zero, i.e., $\Psi(m) \geq 0$.

With a unimodal map, we can use Mitra's (2001) sufficient condition for the existence of topological chaos, which is a weaker sufficient condition than the Li-Yorke theorem (Li and Yorke, 1975).

\section{Theorem 1}

Suppose that $\Psi(m) \geq 0$. If $\Psi$ satisfies $\Psi^{2}(m)>m$ and $\Psi^{3}(m)>\phi^{* *}$, then $(X, \Psi)$ exhibits topological chaos.

Proof: See Mitra (2001).

If an economy satisfies Mitra's condition, the dynamical system $(X, \Psi)$ has a cycle with a period which is not a power of two. ${ }^{12}$ In Eq.(18), if $\alpha=\frac{2}{3}$, $\gamma=\sqrt{3}-1$, and $\mu=\frac{1}{2}$, then the dynamical system exhibits topological chaos, satisfying Mitra's sufficient condition. The formal proof of this claim is upon request. The phase diagram is given by figure 3 .

[Figure 3 around here]

\section{NUMERICAL ANALYSIS}

In this section, we investigate to what type of cycles the economy converges or under what value of $\mu$ the economy exhibit complex dynamics by executing numerical analyses. We keep assuming that $\phi \sim U(0,1)$.

In the following numerical analyses, we allow the minimum of $\Psi\left(\phi_{t}\right)$ to be less than zero, i.e., $\Psi(m)<0$. If $\Psi(m)<0$, then for almost all the initial

\footnotetext{
${ }^{12}$ We consider an upside-down case, whereas Mitra gives a theorem for the usual unimodal case. Therefore, the inequalities in theorem 1 are the reverse of those of Mitra (2001).
} 
values $\phi_{0} \in X$, the sequence, $\left\{\phi_{t}\right\}_{t=0}^{\infty}$, enters $A_{0}=\{\phi \in X: \Psi(\phi)<0\}$ (see figure 4) and escapes from $X$ in finite time. If a sequence $\left\{\phi_{t}\right\}_{t=0}^{\infty}$ escapes from $X$ in finite time, it cannot be an equilibrium. As studied by Boldrin, et al. (2001) in detail, the remaining set of $\phi_{0} \in X$, with which the associated sequence $\left\{\phi_{t}\right\}_{t=0}^{\infty}$ does not enter $A_{0}$, is a Cantor set whose Lebesgue measure is equal to zero. On the Cantor set, if the initial value of $\phi_{0} \in X$ happens to be consistent with the existence of equilibrium, then the sequence $\left\{\phi_{t}\right\}_{t=0}^{\infty}$ will be equilibrium. For instance, if the sequence $\left\{\phi_{t}\right\}_{t=0}^{\infty}$ starts with a stationary value of a period-two cycle as in figure 4 , it becomes an equilibrium. If the sequence $\left\{\phi_{t}\right\}_{t=0}^{\infty}$ starts with the steady state, $\phi^{*}$ or $\phi^{* *}$, then it becomes an equilibrium as well. Moreover, on the Cantor set, the equilibrium path would even display complex dynamics and would exhibit sensitive dependence on initial conditions. ${ }^{13}$ Since the measure of the Cantor set is zero, we will see empty windows in bifurcation diagrams if $\Psi(m)<0$ (see figure 5e below).

\section{[Figure 4 around here]}

To investigate if the economy has a "globally stable" cycle or not, we analyze the dynamical system $(X, \Psi)$ numerically, observing bifurcation diagrams. We create the bifurcation diagrams for the dynamical system $(X, \Psi)$, iterating 10000 times. We set the initial condition to $\phi_{0}=0.01$. It is well known that if for a given $\mu$, a Schwarzian derivative, $S(\Psi):=\frac{\Psi^{\prime \prime \prime}(\phi)}{\Psi^{\prime}(\phi)}-$ $\frac{3}{2}\left(\frac{\Psi^{\prime \prime}(\phi)}{\Psi^{\prime}(\phi)}\right)^{2}<0$ for all $\phi \in X$, then the orbits starting from almost all the initial values of $\phi_{0} \in X$ have the same asymptotic dynamic behavior. Since our Schwarzian derivatives are negative for any value of $\mu \in[0,1)$, the choice of initial conditions is not important. ${ }^{14}$

Figures 5a-5e give bifurcation diagrams with respect to the degree of financial development, i.e., $\mu$. To pin down the value of $\alpha$ is difficult because $z_{t}$ is considered to incorporate human capital as well as physical capital in our model. We utilize the lower limit of the estimation for labor's share of output by Mankiw, et al. (1992). According to them, the lower limit

\footnotetext{
${ }^{13}$ To the best of our knowledge, in the literature of economics, only Boldrin, et al. (2001) deal with equilibria on Cantor sets. See also Devaney (1989).

${ }^{14}$ See Guckenheimer and Holmes (1983) for this point. It is very difficult to verify the sign of our Schwarzian derivative analytically. We numerically confirmed that the signs are negative by plotting the values of our Schwarzian derivatives. Furthermore, we examined various initial values and found that the asymptotic behavior of the dynamical system is invariant to the initial values.
} 
of $1-\alpha$ is estimated as 0.29. Hence, we pin down $\alpha=0.71$. For $\gamma$, we examine various cases: $\gamma=0.63,0.64,0.65,0.66,0.67 .{ }^{15}$ As predicted in the previous section, for all the diagrams, if $\mu$ is small or large, $\left\{\phi_{t}\right\}_{t=0}^{\infty}$ converges to an asymptotically stable steady-state equilibrium. The economy does not exhibit complex dynamics in these cases.

As seen in figure 5a, if $\gamma=0.63$, and if credit constraints are moderate, the economy converges to a period-four cycle asymptotically. In figure 5b where $\gamma=0.64$, as $\mu$ increases from zero, the first period doubling bifurcation occurs around $\mu=0.313$ and the second period doubling bifurcation occurs around $\mu=0.419$. These period doubling bifurcations are repeated over and over again and, eventually, the economy enters a so-called "chaotic region". When $\mu$ decreases from one, the similar things happen. However, it is interesting that from $\mu=0.535$ to $\mu=0.543$, complex dynamics does not appear and that the economy converges to a period-six cycle. Likewise, for the case in which $\gamma=0.66$ in figure $5 \mathrm{~d}$, while the moderate value of $\mu$ gives chaotic regions, the intermediate value of $\mu$ gives a non-complex dynamics. However, when $\gamma=0.65$ in figure $5 \mathrm{c}$, there is no non-complex region sandwiched by two complex regions. When $\gamma=0.67$ in figure $5 \mathrm{~d}$, we can observe an empty window for the dynamics from $\mu=0.53$ to $\mu=0.557$. As discussed before, this is because $\Psi(m)<0$ holds in this region.

[Figure 5 around here]

\section{CONCLUDING REMARKS}

Financial development has serious effects on macroeconomic phenomena, especially on the dynamic properties of economies as studied in this paper. Our findings are as follows: (i) an economy with credit constraints converges to an asymptotically stable steady state if the credit constraints are severe or too soft and (ii) it is possible that deterministic cycles or chaos arise in equilibrium if credit constraints are moderate. From these consequences, we can safely say that it is when the degree of financial development is moderate that an economy is highly volatile. Because this is a testable claim, we can check this prediction empirically.

\footnotetext{
${ }^{15}$ If we assume that the annual subjective discount rate is 0.92 , then $\gamma=0.63$ corresponds to 6.5 years and $\gamma=0.67$ to 8.5 years, which can be reasonably considered as the intermediate-term loan contracts.
} 
The heterogeneous-agent model that we construct in this paper is tractable and can be extended to various research areas such as international trade, international finance, monetary economics, and so on. For example, by constructing similar models to ours, Kunieda (2008) studies efficiency effects of asset bubbles, and Kunieda and Shibata (2011) present an endogenous growth model to derive growth cycles. Kunieda et al. (2014) develop a twocountry model to investigate the effect of capital liberalization on economic growth when there are corrupt bureaucrats in the countries.

\section{References}

[1] Aghion, P. and A. Banerjee (2005) Volatility and Growth. New York: Oxford University Press.

[2] Aghion, P., P. Howitt and D. Mayer-Foulkes (2005). 'The Effect of Financial Development on Convergence: Theory and Evidence', The Quarterly Journal of Economics, 120, 173-222.

[3] Aghion, P., P. Bacchetta and A. Banerjee (2004) 'Financial Development and the Instability of Open Economies', Journal of Monetary Economics 51, 1077-1106.

[4] Aghion, P., A. Banerjee and T. Piketty (1999) 'Dualism and Macroeconomic Volatility', Quarterly Journal of Economics 114, 1359-1397.

[5] Angeletos, G.-M. (2007) 'Uninsured idiosyncratic investment risk and aggregate saving', Review of Economic Dynamics 10, 1-30.

[6] Antrás, P. and R. J. Caballero (2009) 'Trade and Capital Flows: A Financial Frictions Perspective', Journal of Political Economy 117, 701744.

[7] Aoki, K., G. Benigno and N. Kiyotaki (2009) 'Capital Flows and Asset Prices', in R. Clarida and F. Giavazzi (eds), NBER International Seminar on Macroeconomics 2007, Illinois: University of Chicago Press.

[8] Azariadis, C. and B. D. Smith (1998) 'Financial Intermediation and Regime Switching in Business Cycles', American Economic Review 88, 516-536. 
[9] Benhabib, J. and R. H. Day (1982) 'A Characteristic of Erratic Dynamics in the Overlapping Generations Model', Journal of Economic Dynamics and Control 4, 37-55.

[10] Benhabib, J. and G. Laroque (1988) 'On Competitive Cycles in Productive Economies', Journal of Economic Theory 45, 145-170.

[11] Benhabib, J. and K. Nishimura (1985) 'Competitive Equilibrium Cycles', Journal of Economic Theory 35, 284-306.

[12] Bernanke, B. and M. Gertler (1989) 'Agency Costs, Net Worth, and Business Fluctuations', American Economic Review 79, 14-31.

[13] Boldrin, M., K. Nishimura, T. Shigoka and M. Yano (2001) 'Chaotic Equilibrium Dynamics in Endogenous Growth Models', Journal Economic Theory 96, 97-132.

[14] Caballé J., X. Jarque and E. Michetti (2006) 'Chaotic Dynamics in Credit Constrained Emerging Economies', Journal of Economic Dynamics and Control 30, 1261-1275.

[15] Dei, F. (2011) 'Quality of Labor Markets in a Developing Country', Review of International Economics 19, 626-633.

[16] Devaney, R.L. (1989) An Introduction to Chaotic Dynamical Systems, Second Edition. MA: Addison-Wesley Publishing Company.

[17] Denizer, C., M. F. Iyigum and A. L. Owen (2002) 'Finance and Macroeconomic Volatility', Contributions to Macroeconomics 2, Article 7.

[18] Diamond, P.A. (1965) 'National Debt in a Neoclassical Growth Model', American Economic Review 55, 1126-1150.

[19] Easterly, W., R. Islam and J. E. Stiglitz (2000), 'Shaken and Stirred: Explaining Growth Volatility', in B. Pleskovic and N. Stern (eds), Annual World Bank Conference on Development Economics 2000. Washington, DC: World Bank Publications.

[20] Farmer, R. E. A. (1986) 'Deficits and Cycles', Journal Economic Theory $40,77-88$.

[21] Favara, G. (2012) 'Agency Problems and Endogenous Investment Fluctuations', Review of Financial Studies 25, 2301-2342. 
[22] Furukawa, Y. (2010) 'Intellectual Property Protection and Innovation: An Inverted-U Relationship', Economics Letters 109, 99-101.

[23] Gale, D. (1973) 'Pure Exchange Equilibrium of Dynamic Economic Model', Journal Economic Theory 6, 12-36.

[24] Galor, O. (1992) 'A Two-Sector Overlapping-Generations Model: A Global Characterization of the Dynamical System', Econometrica 60, 1351-1386.

[25] Gertler, M. and N. Kiyotaki (2010) 'Financial Intermediation and Credit Policy in Business Cycle Analysis', in B. M. Friedman and M. Woodford (eds), Handbook of Monetary Economics, Vol.3. Amsterdom: NorthHolland.

[26] Guesnerie, R. (1986) 'Stationary Sunspot Equilibria in an $N$ Commodity World', Journal Economic Theory 40, 103-127.

[27] Guckenheimer, J. and P. Holmes (1983) Nonlinear Oscillations, Dynamical Systems, and Bifurcations of Vector Fields. New York: SpringerVerlag New York Inc.

[28] Gokan, Y. (2011) 'Poverty Traps, the Money Growth Rule, and the Stage of Financial Development', Journal of Economic Dynamics and Control 35, 1273-1287.

[29] Grandmont, J. M. (1983) Money and Value. New York: Cambridge University Press.

[30] Grandmont, J. M. (1985) 'On Endogenous Competitive Cycles', Econometrica 53, 995-1046.

[31] Kikuchi, T. (2008) 'International Asset market, Nonconvergence, and Endogenous Fluctuations', Journal of Economic Theory 139, 310-334.

[32] Kikuchi, T. and J. Stachurski (2009) 'Endogenous Inequality and Fluctuations in a Two-country Model', Journal of Economic Theory 144, 1560-1571.

[33] Kikuchi, T. and G. Vachadze (2013) 'Financial Liberalization: Poverty Trap or Chaos', National University of Singapore. 
[34] Kiyotaki, N. (1998) 'Credit and Business Cycles', Japanese Economic Review 49, 18-35.

[35] Kiyotaki, N. (2011) 'A Perspective on Modern Business Cycle Theory', Economic Quarterly 97, 195-208.

[36] Kiyotaki, N. and J. Moore (1997) 'Credit Cycles', Journal of Political Economy 105, 211-248.

[37] Kunieda, T. (2008) 'Asset Bubbles and Borrowing Constraints', Journal of Mathematical Economics 44, 112-131.

[38] Kunieda, T. and A. Shibata (2005) 'Credit Constraints and the Current Account: A Test for the Japanese Economy', Journal of International Money and Finance 24, 1261-1277.

[39] Kunieda, T. and A. Shibata (2011) 'Endogenous Growth and Fluctuations in an Overlapping Generations Economy with Credit Market Imperfections', Asia-Pacific Journal of Accounting \&6 Economics 18, 333357.

[40] Kunieda, T., K. Okada and A. Shibata (2014) 'Corruption, Capital Account Liberalization, and Economic Growth: Theory and Evidence', International Economics (in press), DOI: 10.1016/j.inteco.2014.03.001.

[41] Li, T. Y. and J. A. Yorke (1975) 'Period Three Implies Chaos', American Mathematical Monthly 82 , 985-992.

[42] Ma, Y. and F. Dei (2009) 'Product Quality, Wage Inequality, and Trade Liberalization', Review of International Economics 17, 244-260.

[43] Mankiw, N. G. Romer, D. and D. N. Weil (1992) 'A Contribution to the Empirics of Economic Growth', Quarterly Journal of Economics 107, 407-437.

[44] Matsuyama, K. (2007) 'Credit Traps and Credit Cycles', The American Economic Review 97, 503-516.

[45] Matsuyama, K. (2013) 'The Good, the Bad, and the Ugly: An Inquiry into the Causes and Nature of Credit Cycles', Theoretical Economics 8, 623-651. 
[46] Mitra, T. (2001) 'A Sufficient Condition for Topological Chaos with an Application to a Model of Endogenous Growth', Journal Economic Theory 96, 133-152.

[47] Nishimura, K. and M. Yano (1995) 'Nonlinear Dynamics and Chaos in Optimal Growth: An Example', Econometrica 63, 981-1001.

[48] Orgiazzi, E. (2008) 'Financial Development and Instability: The Role of the Labour Share', Research in Economics 62, 215-236.

[49] Paasche, B. (2001) 'Credit Constraints and International Financial Crises', Journal of Monetary Economics 48, 623-650.

[50] Pintus, P. (2011) 'International capital flows, debt overhang and volatility', International Journal of Economic Theory 7, 301-315.

[51] Raddatz, C. (2006) 'Liquidity Needs and Vulnerability to Financial Underdevelopment', Journal of Financial Economics 80, 677-722.

[52] Reichlin, P. (1986) 'Equilibrium Cycles in an Overlapping Generations Economy with Production', Journal Economic Theory 40, 89-102.

[53] Rochon, C., and H. M. Polemarchakis (2006) 'Debt, Liquidity and Dynamics', Economic Theory 27, 179-211.

[54] Samuelson, P. (1958) 'An Exact Consumption-loan Model of Interest with or without the Social Contrivance of Money', Journal of Political Economy 66, 467-482.

[55] Savtchenko, L. (2010) 'Foreign Devaluation as a Coordinating Device of Heterogeneous Investors: A Game-theoretic Analysis of Financial Contagion', International Journal of Economic Theory 6, 195-204.

[56] Suarez, J. and O. Sussman (1997) 'Endogenous Cycles in a StiglitzWeiss Economy', Journal of Economic Theory 76, 47-71.

[57] Yano, M. (2008) 'Economic Analysis of Market Quality', in Makoto Yano (ed), The Japanese Economy - A Market Quality Perspective. Tokyo: Keio Univeristy Press.

[58] Yano, M. (2009) 'The Foundation of Market Quality Economics', Japanese Economic Review 60, 1-32. 


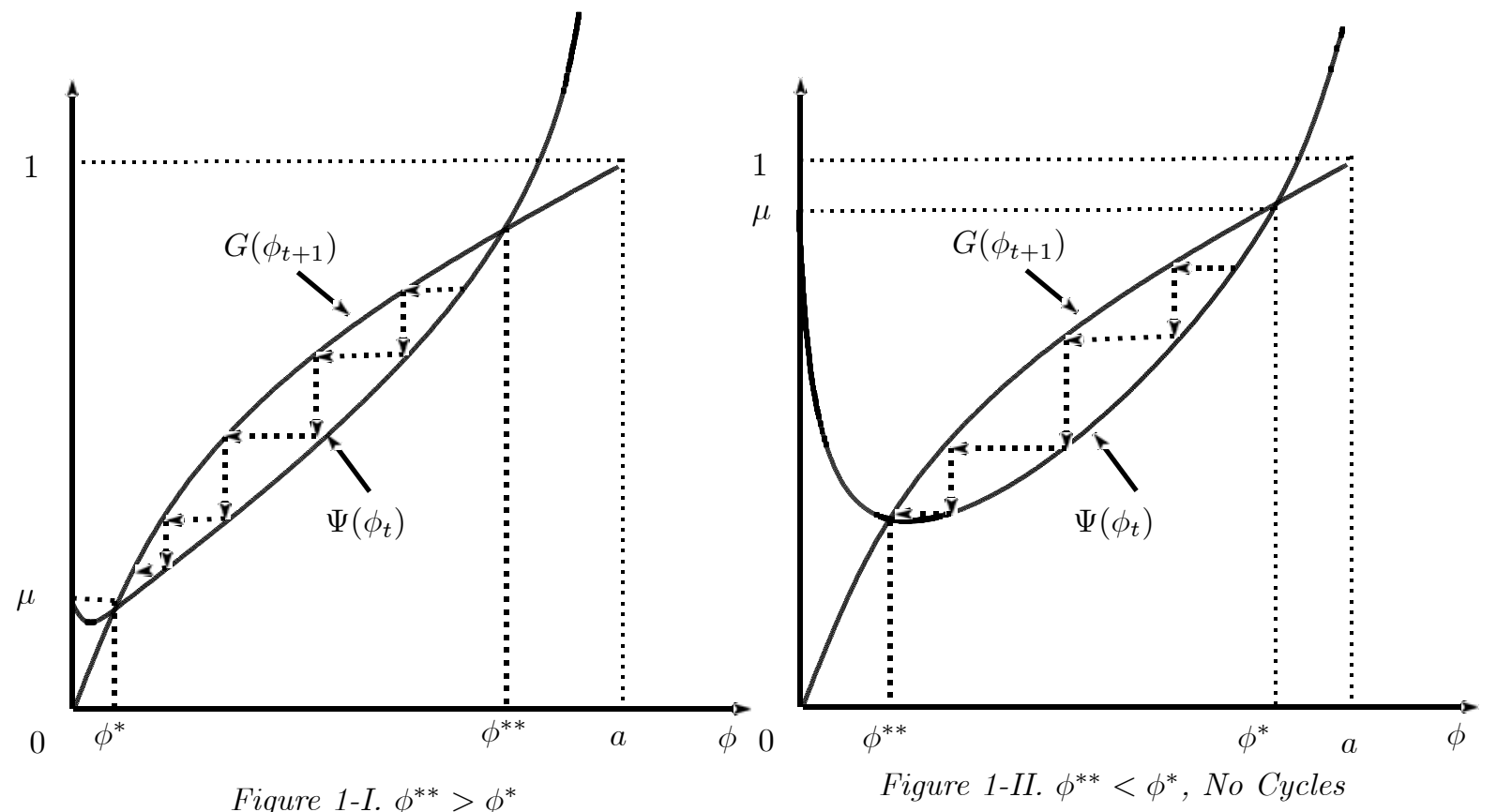

Figure 1-I. $\phi^{* *}>\phi^{*}$

Figure 1-II. $\phi^{* *}<\phi^{*}$, No Cycles

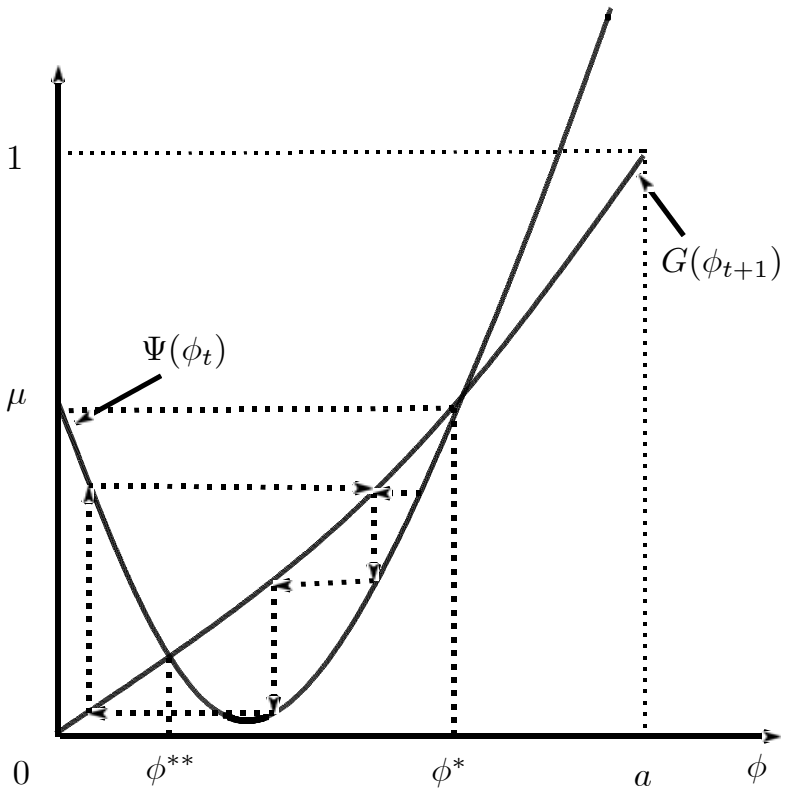

Figure 1-III. $\phi^{* *}<\phi^{*}$, Cycles or Chaos

Figure 1. Phase diagrams 


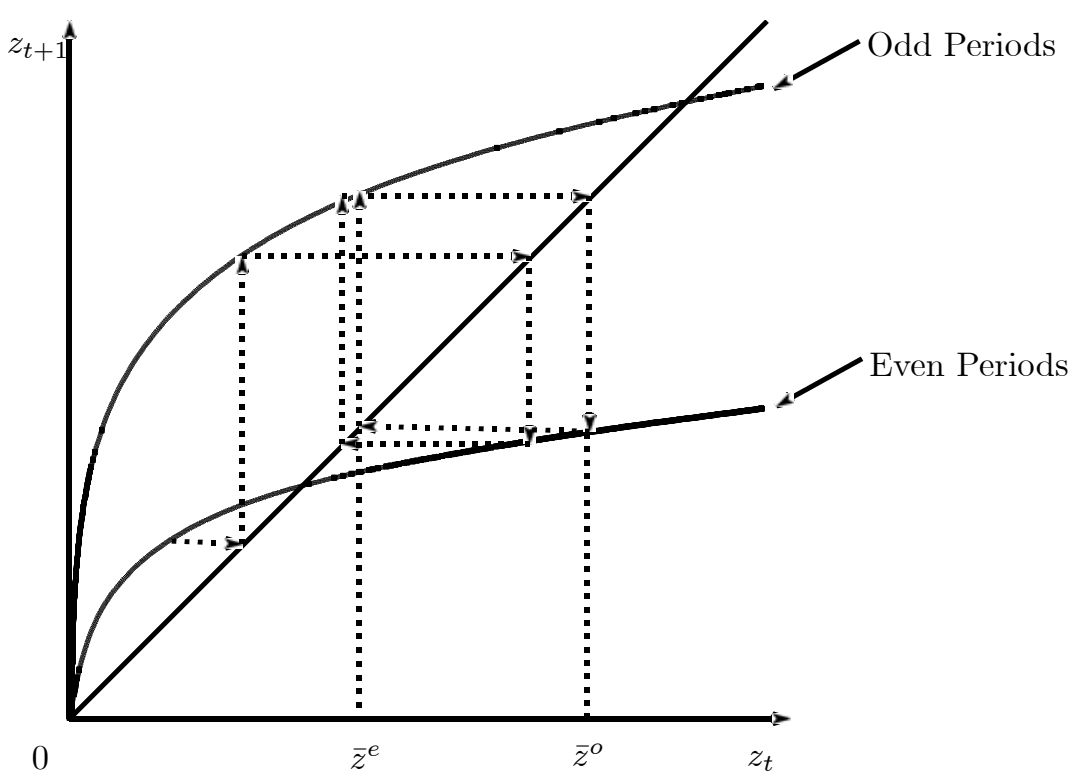

Figure 2. Period-Two Cycle 


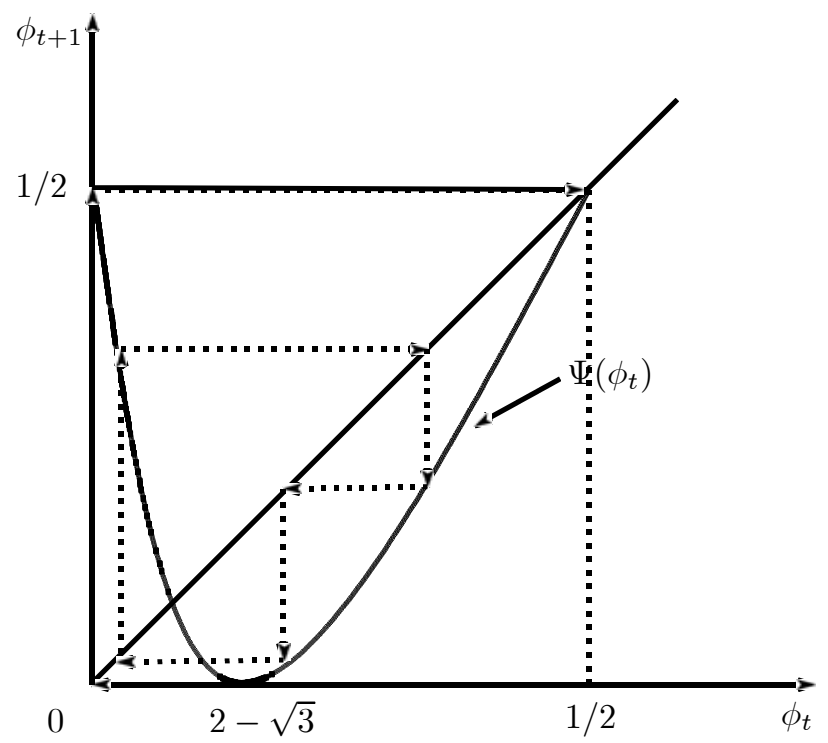

Figure 3. Topological Chaos

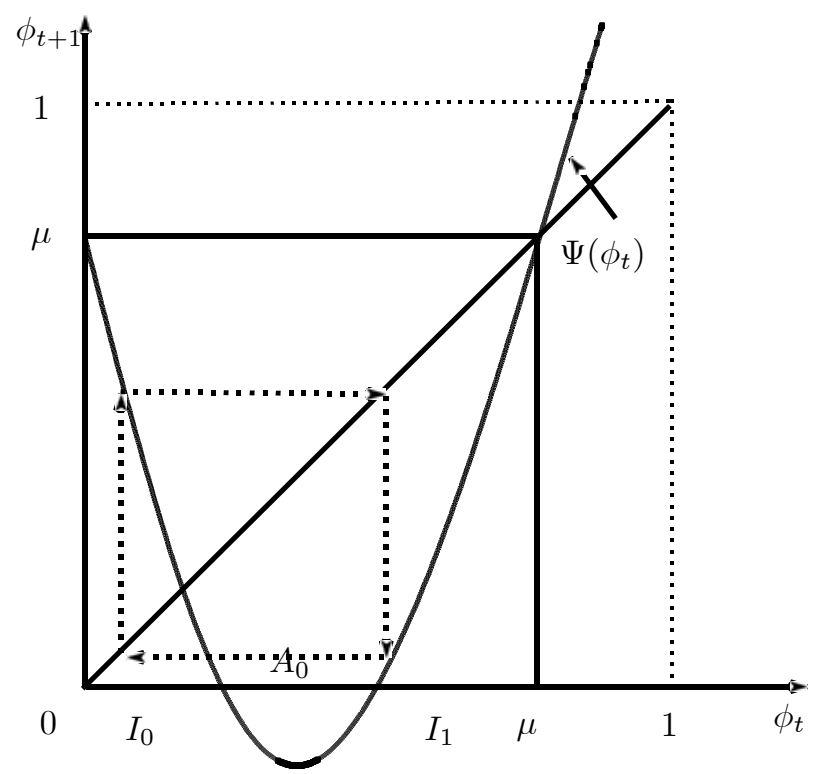

Figure 4. Case of $\Psi(m)<0$ 
Vertical axis: $\phi_{t}$

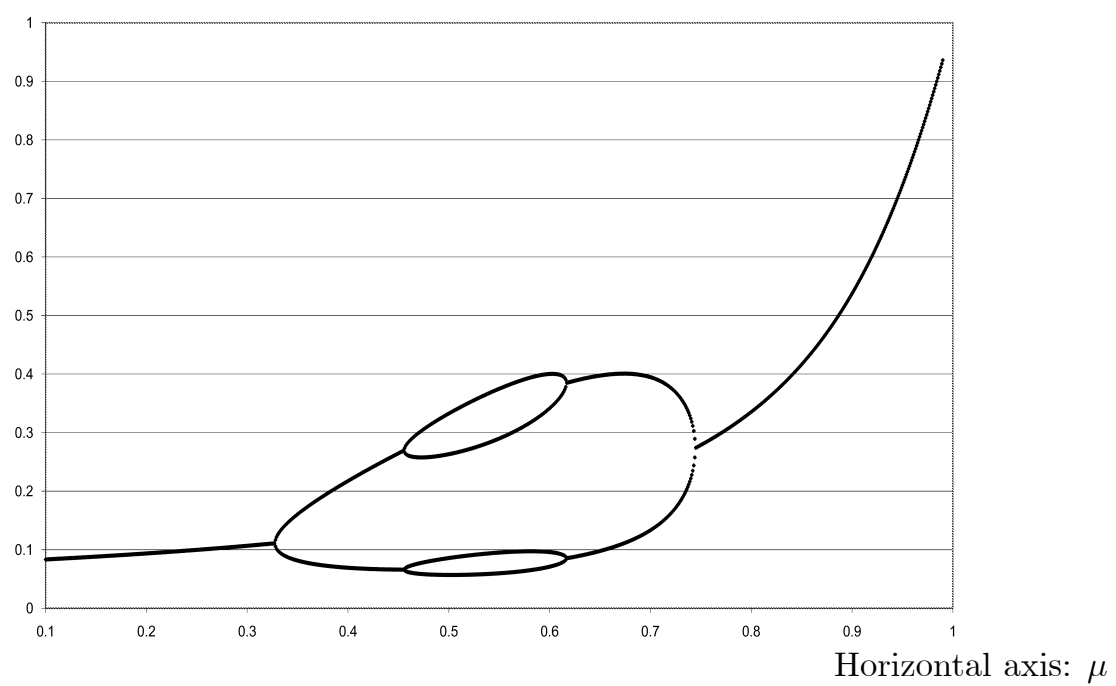

Figure 5a. Bifurcation Diagram for phi, Gamma=0.63

Vertical axis: $\phi_{t}$

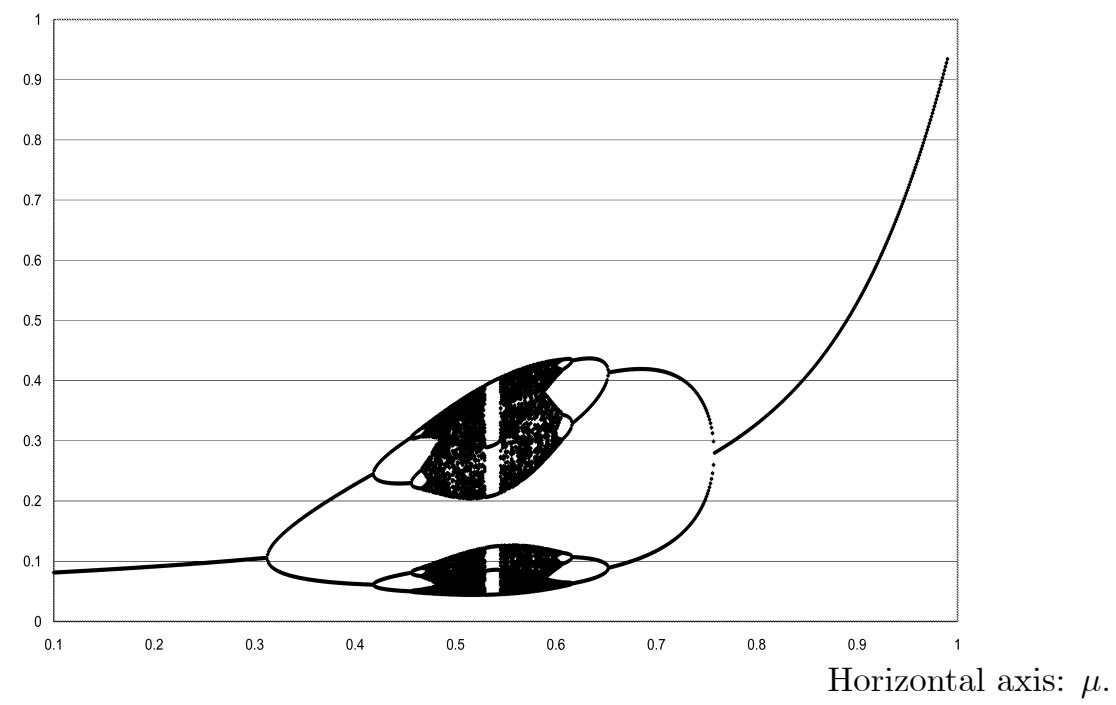

Figure 5b. Bifurcation Diagram for phi, Gamma=0.64 
Vertical axis: $\phi_{t}$

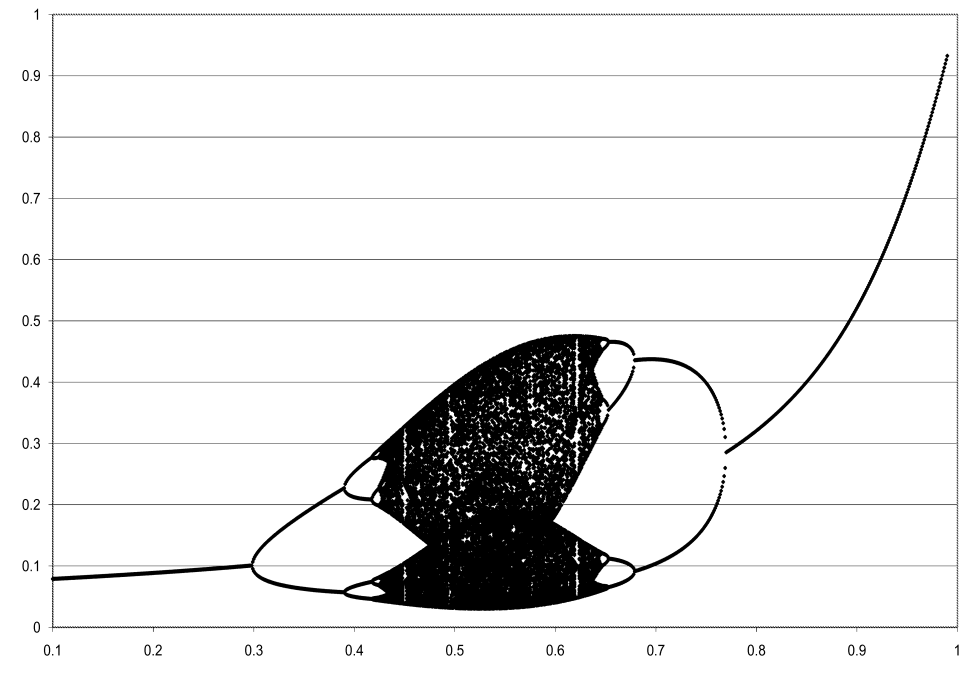

Horizontal axis: $\mu$

Figure 5c. Bifurcation Diagram for phi, Gamma=0.65

Vertical axis: $\phi_{t}$

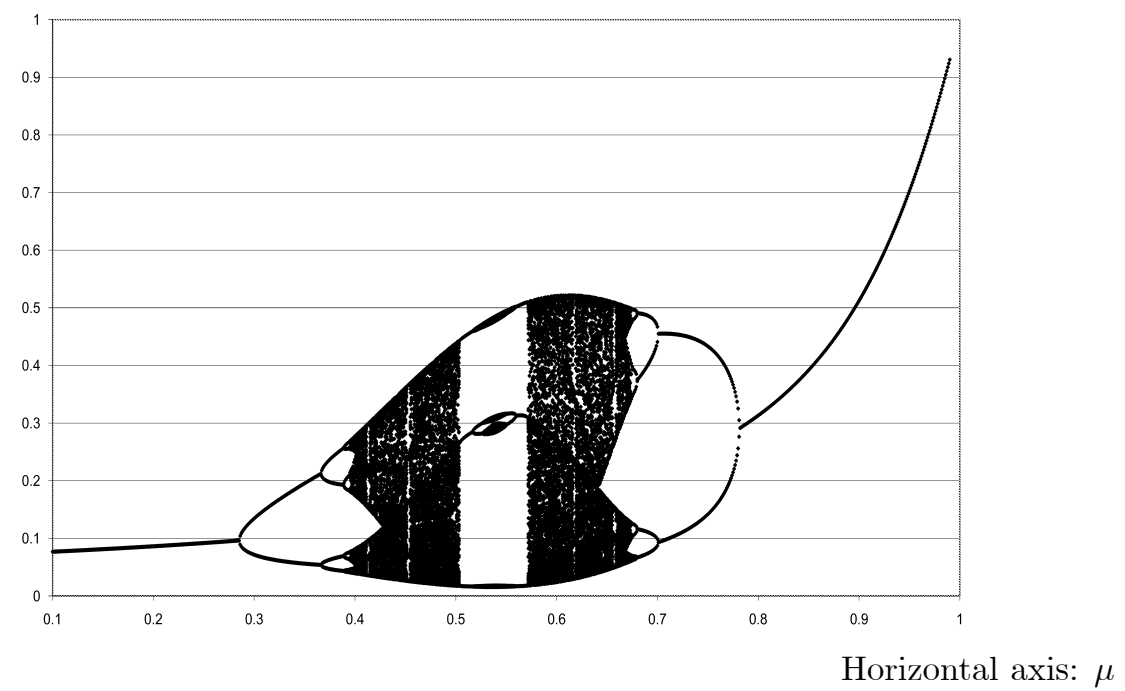

Figure 5d. Bifurcation Diagram for phi, Gamma=0.66 
Vertical axis: $\phi_{t}$

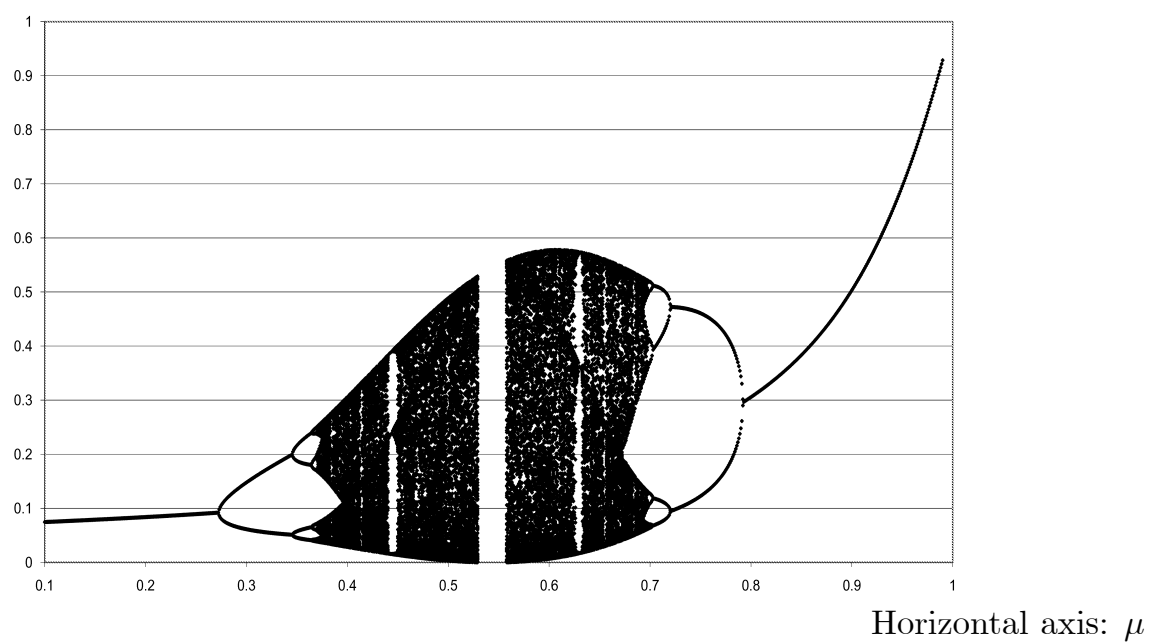

Figure 5e. Bifurcation Diagram for phi, Gamma=0.67 